\title{
Production of Injection Molding Tooling with Conformal Cooling Channels using The Three Dimensional Printing Process
}

\author{
Emanuel Sachs ${ }^{1}$, Samuel Allen ${ }^{2}$, Michael Cima ${ }^{2}$, Edward Wylonis ${ }^{1}$, and Honglin Guo ${ }^{2}$ \\ ${ }^{1}$ Department of Mechanical Engineering \\ 2Department of Materials Science and Engineering \\ Massachusetts Institute of Technology \\ Cambridge, Massachusetts 02139
}

\begin{abstract}
Three Dimensional Printing is a desktop manufacturing process in which powdered materials are deposited in layers and selectively joined with binder from an ink-jet style printhead. Unbound powder is removed upon process completion, leaving a three dimensional part. Stainless steel injection molding inserts have been created from metal powder with the 3DP process.

The freedom to create internal geometry by the use of the 3D-Printing process allows for the fabrication of molds with complex internal cooling passages. Tooling was developed with cooling channels designed to be conformal to the molding cavity. A finite difference simulation was constructed to study conformal channel design.

A direct comparison of the mold surface temperature during the injection cycle of a 3D Printed mold with conformal channels and a mold machined with conventional straight channels was completed. The conformal passages produced with the 3DP process provide the ability to accurately control the temperature of the molding cavity throughout the process cycle. Surface temperature measurements demonstrated that the inserts with conformal cooling channels exhibited a more uniform surface temperature than the inserts machined with straight channels.
\end{abstract}

Issues such as powder removal and post processing of green parts with small cooling channels were investigated.

\section{A. Motivation}

\section{INTRODUCTION}

The injection molding process is one of the most widely used methods of manufacturing polymer plastic products. Many parts that are injection molded today have very rigid tolerance requirements. Proper thermal management of metal injection molding tooling is necessary to increase part quality and production rates. Cooling passages placed in the tooling manage the heat flow out of the plastic. Current fabrication methods place severe limitations on the configuration of the cooling channels used for heat withdrawal.

The freedom to create internal geometry by the use of the 3D-Printing process allows for the fabrication of molds with complex internal cooling passages. These cooling channels can be designed to be conformal to the molding cavity. Conformal passages produced with the 3DP process provide the ability to control more accurately the temperature of the molding cavity throughout the process cycle. Such temperature control has the potential to produce parts with lower residual stresses and to shorten cycle times. 


\section{B. Current Mold Cooling Practices}

Cooling in cavity geometries is typically accomplished by routing straight cooling channels around the part cavity. The cooling circuits are positioned around the part cavity as uniformly as the part shape will allow and as close to the cavity walls as possible. The number and size of the cooling circuits are often limited by the part's ejector system. Often, it is not possible to place cooling channels in the inserts. Channels must be placed in the bolsters or support blocks instead. In this case the interface between the bolster and the insert is critical. A thin layer of air at this interface can act as an insulator and hinder heat withdrawal. Short and independent routings yield the best temperature control performance. Parallel cooling circuits as opposed to series cooling circuits are considered a better cooling method. Short parallel circuits do not allow the coolant to heat up in the mold and offer more consistent and uniform temperature control [Gordon, 1993].

Cooling of the core insert is the greatest problem in most injection molding applications. Often, no cooling is employed in the core itself. Cooling only occurs in the mold base through the core mount. With no core cooling, eventual heating of the core is unavoidable.

Cooling of slender cores is often accomplished by using inserts made of materials with high thermal conductivity, such as copper, beryllium-copper or high-strength sintered copper-tungsten materials. [Menges, 1993] These metal inserts are press-fitted into the slender core and extend into the mold base. The high thermally conductive insert usually extends into the flow of coolant in a cooling channel. A major concern in utilizing this core cooling method is maintaining an extremely tight press-fit. If there is a poor fit, the resulting thin layer of air between the high thermally conductive insert and the hole in the core will act as an insulator to heat transfer.

A baffle is a common cooling method in those cases in which coolant is directly channeled through the core. A baffle usually employs a flat or spiral divider in a hole running through the center of the core. The inlet and return flow is separated. This method provides maximum cross sections for the coolant to flow through. The divider must be mounted exactly in the center of the hole to ensure that the coolant does not bypass the hole.

The most effective cooling of slender cores is achieved with bubblers. An inlet tube directs the coolant into a blind hole in the core. The diameters of both have to be adjusted in such a way that the resistance to flow in both cross sections is equal. Bubblers are commercially available and are usually screwed into the core. One problem with baffles and bubbler cooling systems is that the necessary hollow center can result in a structurally weak core insert. [Menges, 1993]

\section{Three Dimensional Printing - Application to Injection Molding Tooling}

Three Dimensional Printing (3DP) is a process for the rapid fabrication of three dimensional parts directly from computer models [Sachs et al, 1990]. A solid object is created by printing a sequence of two-dimensional layers. The creation of each layer involves the spreading of a thin layer of powdered material followed by the selective joining of powder in the layer by ink-jet printing of a binder material. A continuous-jet printhead is raster scanned over each layer of powder using a computer controlled $\mathrm{x}-\mathrm{y}$ table. Individual lines are stitched together to form $2 \mathrm{D}$ layers, and the layers are stitched together to form a 3D part. Unbound powder temporarily supports unconnected portions of the component, allowing overhangs, undercuts and internal 
volumes to be created. The unbound powder is removed upon process completion, leaving the finished part. The 3D Printing process sequence is shown in Fig. 1.

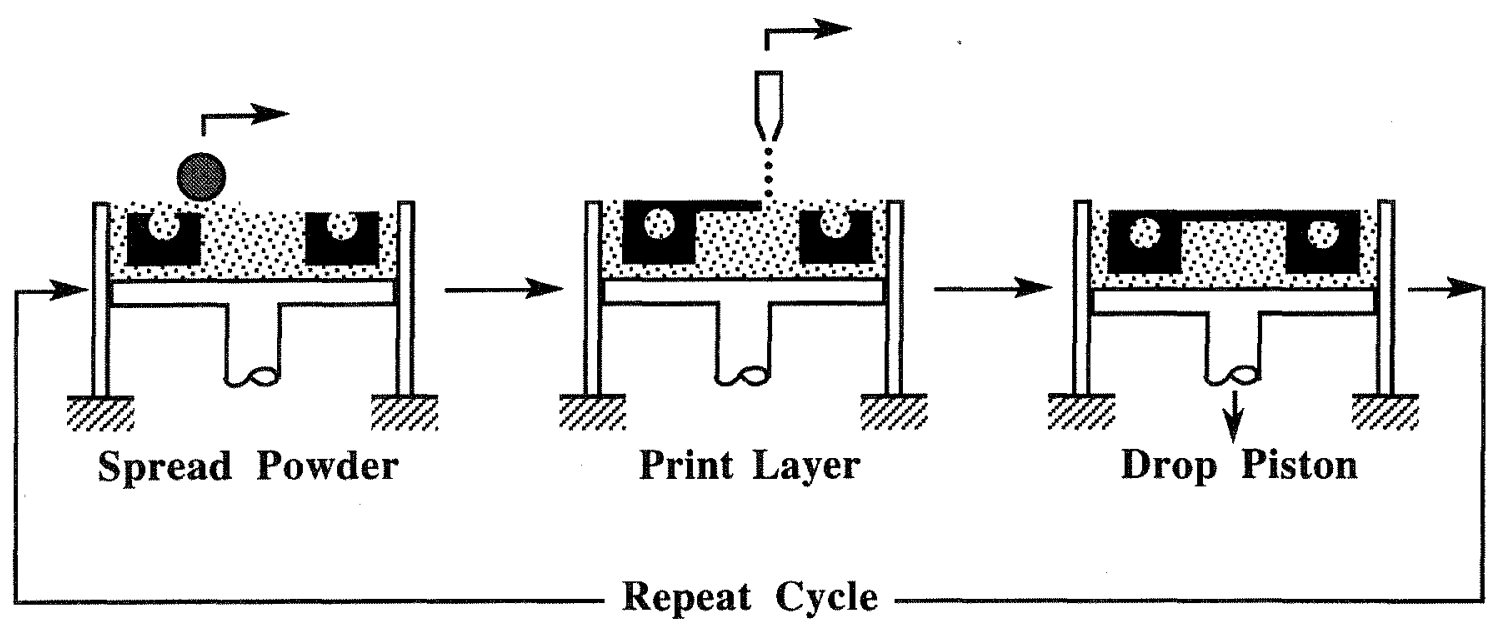

Fig. 1. The 3D Printing sequence.

3D Printing was initially developed for the production of ceramic shells and cores to be later used for the casting of metal parts. In this embodiment of the process, alumina powder is spread into the powder piston and selectively bound using colloidal silica as a binder. After completion of printing, the part is fired in a furnace to further bond the silica to the alumina and strengthen the part sufficiently so that it can be used as a ceramic mold. [Sachs, 1992]

An important aspect of the 3D Printing process its inherent flexibility with respect to materials systems. Although developed around alumina powder and silica binder, many types of powders and binders may be used. This research effort employs the 3D Printing process for the direct fabrication of metal injection molding tooling with conformal cooling channels. Stainless steel (316L) powder is selectively bound with a latex emulsion binder using the 3DP process resulting in a green part. A series of post-processing steps similar to those found in powder metallurgy processing are used to obtain all-metal injection molding tooling with conformal cooling passages. Detailed information on the specific exploration of the application of 3D Printing to the production of metal parts and injection molding tooling is provided by Michaels. [Michaels, 1995]

\section{FABRICATION}

\section{A. Introduction}

The overall process of creating a metal part may be divided into several steps. First, the green part is printed using the 3DP system by using a temporary organic binder. Powder must then be removed from the insert cavities and cooling channels. The green part is then subjected to a series of post processing steps. 
The first step in post-processing the green part is to debind and sinter the part. In debinding, the organic binder used in the 3D Printing process thermally decomposes in an inert gas furnace. Metal skeletons have sufficient strength to be handled after debinding, however, it is advantageous to sinter the part in the same firing schedule at a higher temperature to increase its strength. Finally, the part is infiltrated with a lower melting point alloy to $100 \%$ density.

\section{B. Printing Green Tooling Inserts}

The powder used in creating green 3D Printed tooling was a $316 \mathrm{~L}$ spherical stainless steel powder with a size range of $60 \mu \mathrm{m}$ from Anval Corp. of Rutherford, NJ. An aqueous acrylic copolymer emulsion (Acrysol) from Rohm and Haas of Philadelphia, PA was used as the binder. Typical packing density of the printed part is approximately $60 \%$. A typical 3DP green part is $10 \%$ by volume binder, leaving approximately $30 \%$ open porosity.

After completion of the printing process the entire powder bed is allowed to air dry for a period of 24 hours. The inserts are then placed in an oven at $100^{\circ} \mathrm{C}$ for one to two hours to completely cure the acrylic binder. The green part is then removed from the powder bed. The remaining attached powder on the exterior of the insert is easily blown off with compressed air.

Fig. 2 is a photograph of a large tooling insert in the green state and final infiltrated state.

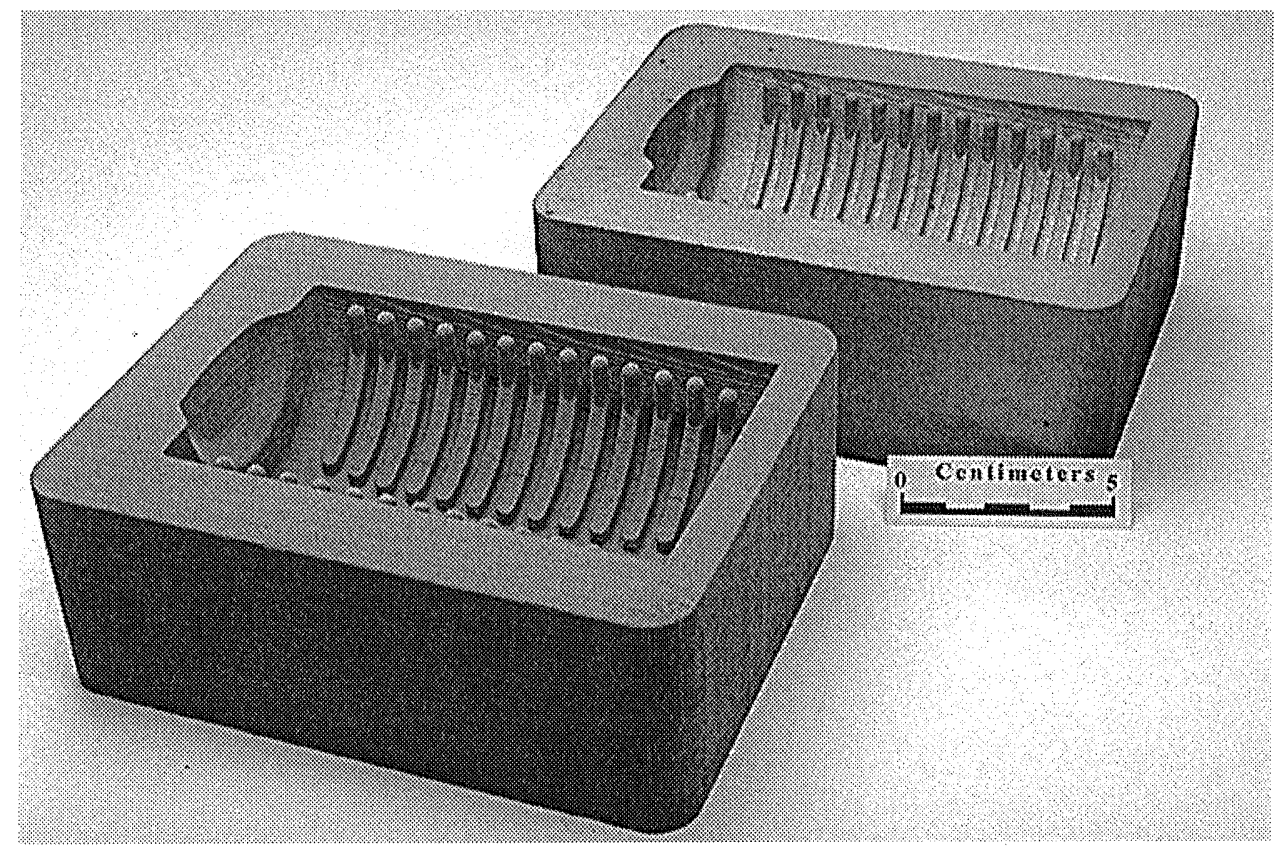

Fig. 2. A large 3D Printed tooling insert in the green (left) and final - infiltrated (right) states. 


\section{Powder Removal from Conformal Cooling Channels}

After printing, complex cavities and cooling channels of the green metal part must be cleared of powder. In order to test the ability to remove powder from complex passages a powder removal test shell was designed. This experiment was devised to evaluate the minimum size cooling channel that could be cleared of powder. A thin box shaped shell was designed such that it could be easily split open and the contents of the channels could be viewed. One of the middle layers of the part contains only thin connection lines that were printed between the channels and around the perimeter of the shell. The lines printed between the channels prevent powder from jumping from one channel to the next during powder removal. The line printed around the perimeter of the part aids in securing the top of the shell to the bottom. Because only these few lines fasten the top of the shell to the bottom, this weak layer acts as a delamination layer providing easy separation of the top of the shell after the powder removal experiment has been conducted. Fig. 3 is a schematic of the five centimeter long test shell containing three straight channels and one zig-zag channel. The smallest channel in the shell has a nominal channel width of $525 \mu \mathrm{m}$. The middle channel is 875 $\mu \mathrm{m}$ wide, and the largest channel and the zig-zag channel are $1.225 \mathrm{~mm}$ wide. All channels are 2 mm deep.

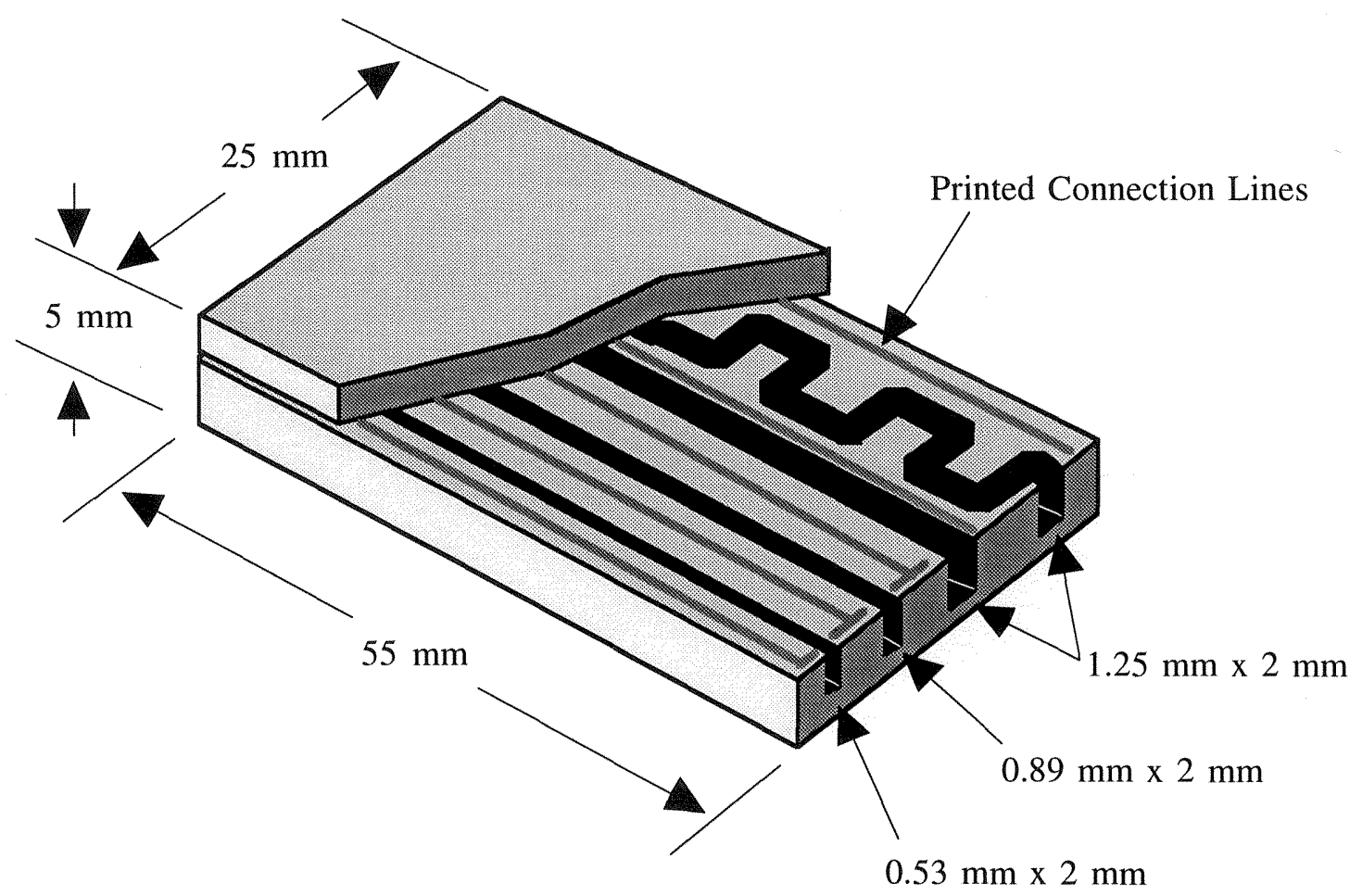

Fig. 3. Schematic of opened powder removal test shell.

The method used to clear the test shell involves placing the green part in a bath of water. This powder removal technique adds a requirement that the polymeric binder in the green part be able to withstand water immersion for a period of time without resulting in distortion of the green part. Fig. 4 shows a picture of a powder removal shell cleared using the water bath procedure. All channels were cleared using this technique and the green part suffered negligible distortion. 


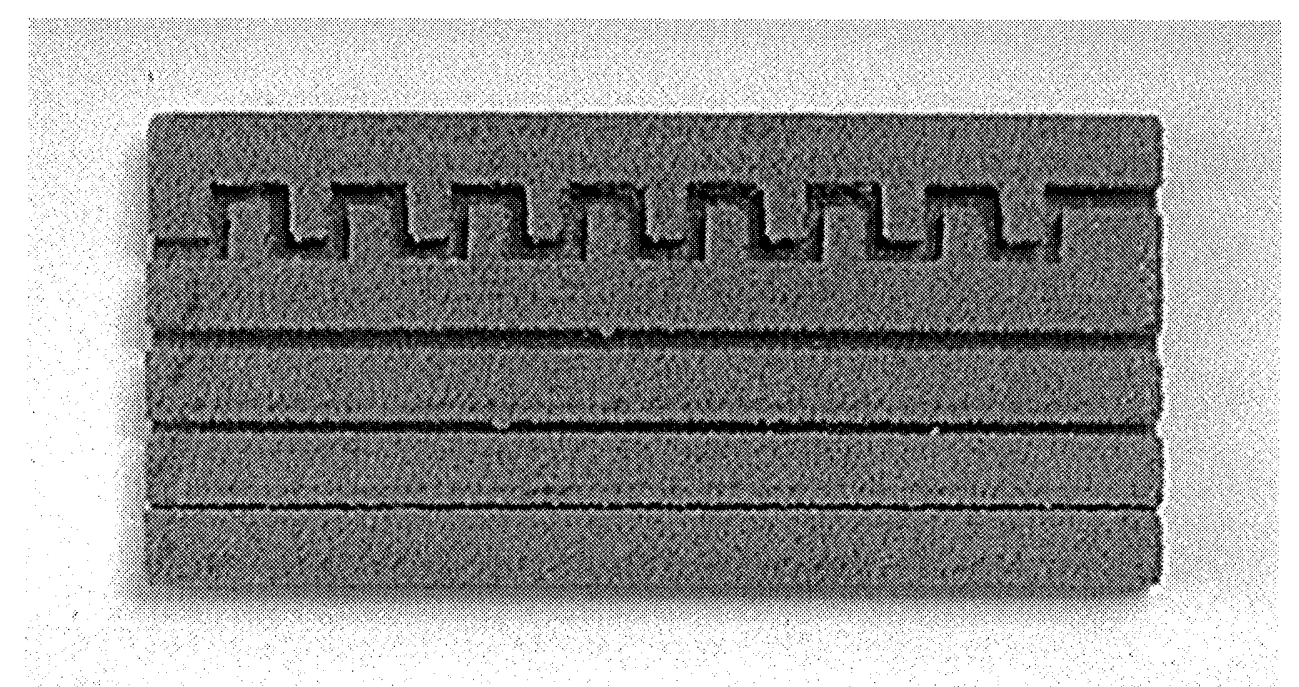

Fig. 4. Opened powder removal test part cleared with soda water vacuum powder removal procedure.

\section{Debinding and Sintering of Green 3D Printed Inserts}

After printing and powder removal, the part is processed using techniques similar to those used in metal injection molding (MIM) with the advantage that the green part has open porosity which greatly facilitates the removal of binder. In debinding, the organic binder used in the 3D Printing process thermally decomposes in an inert gas furnace. Metal skeletons have sufficient strength to be handled after debinding, however, it is advantageous to sinter the part in the same firing schedule at higher temperature to increase its strength.

Debinding and sintering was executed in an Argon / 5\% Hydrogen atmosphere tube furnace. The binder polymer chains are broken by heating during thermal decomposition and the binder is evolved as a gaseous product. Firing yields parts with a final density of $64 \%$ of theoretical. A dimensional change of approximately $-1.5 \%$ is exhibited in large tooling inserts.

\section{MOLD DESIGN AND TESTING}

\section{A. How Close is Close Enough}

A useful guide to the design of conformal cooling channels is a consideration of how close they have to be to the surface to exert significant influence over the temperature at the surface of the molding cavity. If we consider that prior to injection, the tool is at a uniform temperature equal to the coolant temperature, we see that the first portion of heat conducted into the tool will go toward warming up the portion of the tool which lies between the surface and the cooling passage. This observatioin can be used as the basis of a 1-dimensional model which provides guidance to cooling passage placement. 
Consider a 1-D heat flow in a tool where the distance from the mold surface to the closest part of the cooling channel is $d$. Let us assume that when the plastic is first injected, the surface of the tool quickly rises to the melt temperature, $\mathrm{T}_{\mathrm{m}}$. If the tool where under a steady state condition, a linear temperature profile would develop droping from $T_{m}$ at the surface to $T_{c}$, the temperature of the coolant at the passage. If no heat is removed by the coolant, the amount of heat that must be conducted into the tool to reach this condition is:

$$
\text { Heat flow into tool per unit area }=\rho c_{p} d\left(\frac{T_{m}+T_{c}}{2}-T_{c}\right)=\rho c_{p} d \frac{T_{m}-T_{c}}{2}
$$

where $\rho$, and $c_{p}$ are the density and specific heat of the tool material respectively.of the tool material and it is assumed that the tool materail between the surface and the channel reaches a temperature which is an average of $T_{m}$ and $T_{c}$. This heat must be conducted into the tool by a heat flux which may be approximated as:

$$
\text { Heat flux per unit area }=k \frac{T_{m}-T_{c}}{d}
$$

The time required to warm up the tool, $\tau$ can now be calculated by dividing equation (3) by equation (4) :

$$
\tau=\frac{\rho c_{p}}{k} d^{2}
$$

In order to funciton as a conformal cooling channel, $\tau$ must be significantly less that the cycle time, $\tau_{\mathrm{cycle}}$ of the tool which leads to the condition:

$$
d<\sqrt{\frac{k \tau_{c y c l e}}{\rho c_{p}}}=\sqrt{\alpha \tau_{c y c l e}}
$$

where $\alpha$ is the thermal diffusivity of the tool material.

For a typical cycle time of $10 \mathrm{sec}$ and using the thermal diffusivity of the 3D Printed tool material $\left(0.6 \times 10^{-5} \mathrm{~m}^{2} / \mathrm{s}\right)$, we can calculate the condition $\mathrm{d}<8 \mathrm{~mm}$ as the requirement for a channel to behave as a conformal channel.

\section{B. Design of Experimental Inserts}

A ring shaped geometry was chosen for the plastic part design. A gap in the ring was designed to demonstrate clearly any distortion in the part. It was designed such that residual stress buildup in the part would exhibit itself in the form of the ring gap opening or closing. The ring shape is applicable to a core / cavity design that is simple enough to be modeled. A schematic drawing of the simple ring geometry is shown in Fig. 5 below. 


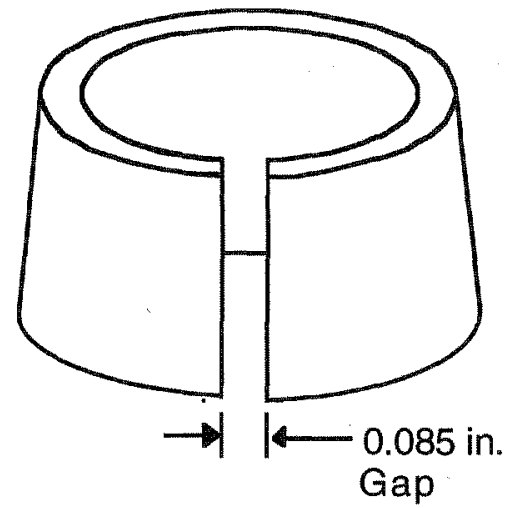

(A)

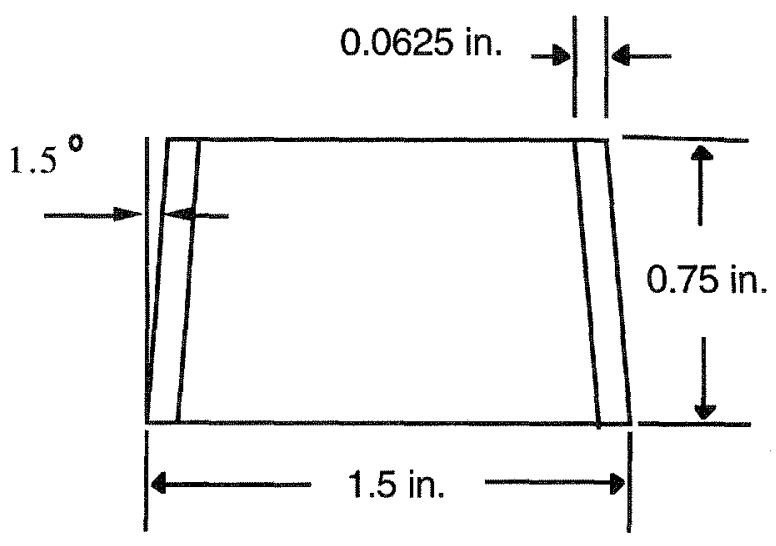

(B)

Fig. 5. Isometric (A) and cross-section (B) schematics of polystyrene part geometry

The cavity insert is a rectangular block having a length of 3.5 inches, width of 3.0 inches and height of 1.5 inches. Fig. 6 describes the basic features of this insert. The cavity insert was designed to fit in a slot milled in a Modular Unit Die (MUD) frame assembly block. A $1.5^{\circ}$ tapered end mill was used to apply draft to the cavity wall for easy part release. A standard sprue-runnergate system was employed. The gate machined in the top face of the insert was 0.032 inches wide and 0.032 inches deep. Three thermocouple holes were drilled next to the cavity wall for surface temperature measurement.

The core insert consists of a rectangular base with a cylindrical shaped core. The rectangular base has a length of 3.5 inches, width of 3.0 inches and a height of 0.5 inches. Fig. 7 describes the basic features of this insert. The cylindrical shaped core sticks out of the top of the rectangular base. The wall of the core has a $1.5^{\circ}$ taper matching the draft angle of the cavity wall. Again, this draft angle ensures easy release of the plastic part from the core.

The cylindrical core was designed with a rib to create the gap in the ring geometry. Two flat parallel walls were required for ease of gap width measurement. Thus, the rib on the core insert was machined such that the two walls of the rib were parallel. Three thermocouple holes were drilled next to the core wall for surface temperature measurements.

The mold assembly utilizes a pair of mild steel assembly blocks in a MUD frame. Recesses were milled in the assembly blocks to accommodate the two inserts. A simple ejector plate / return spring assembly was used for the ejector system.

The first inserts made were created from 303 stainless steel. This material was selected because it offered the best match of thermal conductivity with 3D Printed 316L stainless steel infiltrated with bronze while offering relatively easy machining. The thermal conductivity of the 303 stainless steel is $16.5 \mathrm{~W} / \mathrm{m}-{ }^{\circ} \mathrm{C}$ [Lyman, 1961] and the experimentally determined thermal conductivity of the $3 \mathrm{D}$ Printed material is $22 \mathrm{~W} / \mathrm{m}-{ }^{\circ} \mathrm{C}$.

Core and cavity inserts were machined from 303 stainless steel. Conventional straight cooling channels were machined in these inserts for experimental comparison with the 3D Printed inserts having conformal cooling channels. The diameter of the channels drilled in the 303 stainless steel inserts were designed to have the same cross sectional diameter as the conformal channels in the 3D Printed inserts. A cooling channel cross sectional diameter of $4.76 \mathrm{~mm}$ was chosen. 


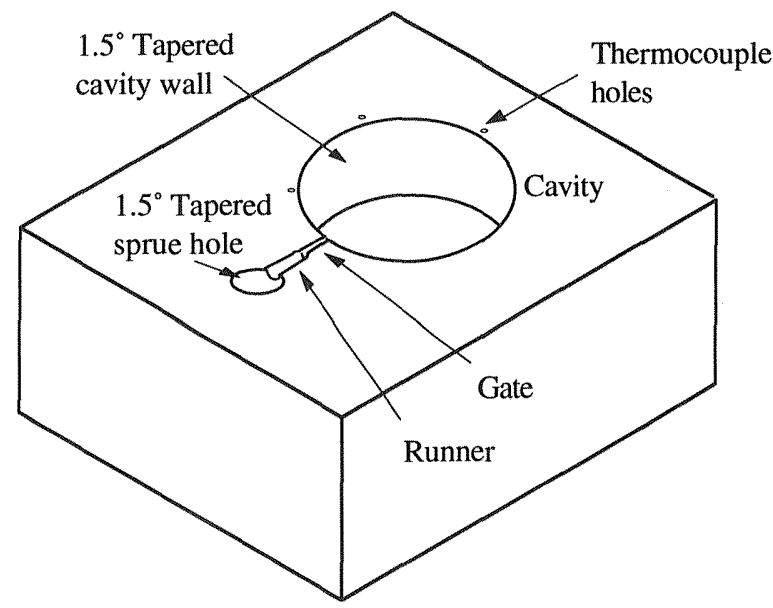

Fig. 8. Cavity insert design.

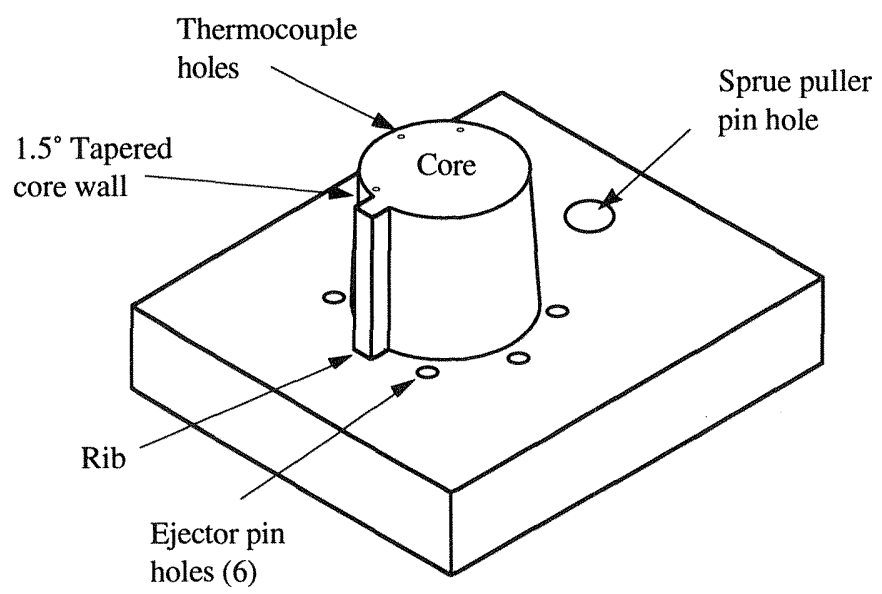

Fig. 9. Core insert design.

Two straight channels were drilled in the cavity insert as shown in Fig. 8(A). These channels were drilled in-between the cavity wall and the sprue. The two channels were spaced evenly along the depth of the cavity. Fig. 8(B) depicts channel placement in the core insert. Three straight channels were drilled in the rectangular base of the insert below the actual core. Placement of cooling channels in these inserts was limited due to the ejector pin placement.

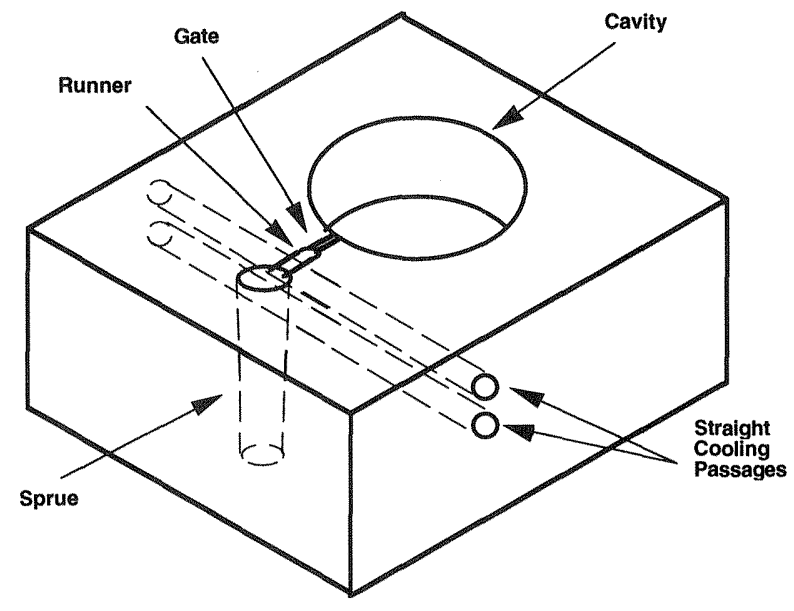

(A)

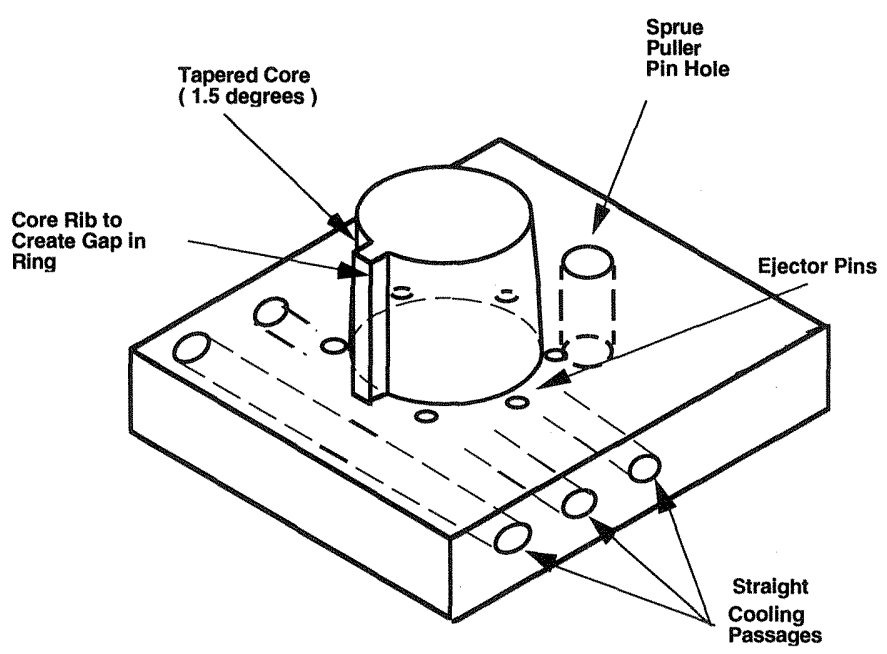

(B)

Fig. 8. Cooling channel placement in the 303 stainless steel cavity (A)and core (B) inserts.

Fig. 9 depicts the infiltrated and machined 3D Printed cavity and core inserts with conformal cooling channels. A polystyrene ring molded with these inserts in also shown. Schematics of the cooling channel placement in these inserts are shown in Fig. 10. Fig. 11 is a photograph of two 3D Printed infiltrated core inserts. One insert has been cut open to reveal the conformal channels inside. 
Two separate conformal channels were designed in the 3D Printed cavity insert. Each separate channel splits $3.18 \mathrm{~mm}$ from the cavity wall into two channels, well below the $8 \mathrm{~mm}$ calculated using equation (6) above. These two channels follow the circular shape of the cavity wall and converge to one exit channel. This channel placement forms a torus shaped passage surrounding the molding cavity. This torus shape keeps the channels $3.18 \mathrm{~mm}$ from the molding surface along the entire perimeter of the cavity. All channels are circular in cross-section and have a diameter of $4.76 \mathrm{~mm}$ matching the straight channels in the 303 stainless steel inserts. The two torus shaped channels were spaced evenly along the depth of the cavity.

As in the 3D Printed cavity design, two torus shaped channels were horizontally spaced along the height of the core. Again, the torus shape keeps the channels $3.18 \mathrm{~mm}$ from the molding surface along the entire perimeter of the core. A single horizontal channel open on the side of the base of the insert connects with a vertical channel underneath the core. This vertical channel intersects the two torus shaped channels. An identical channel path on the opposite side of the core provides a channel exit.

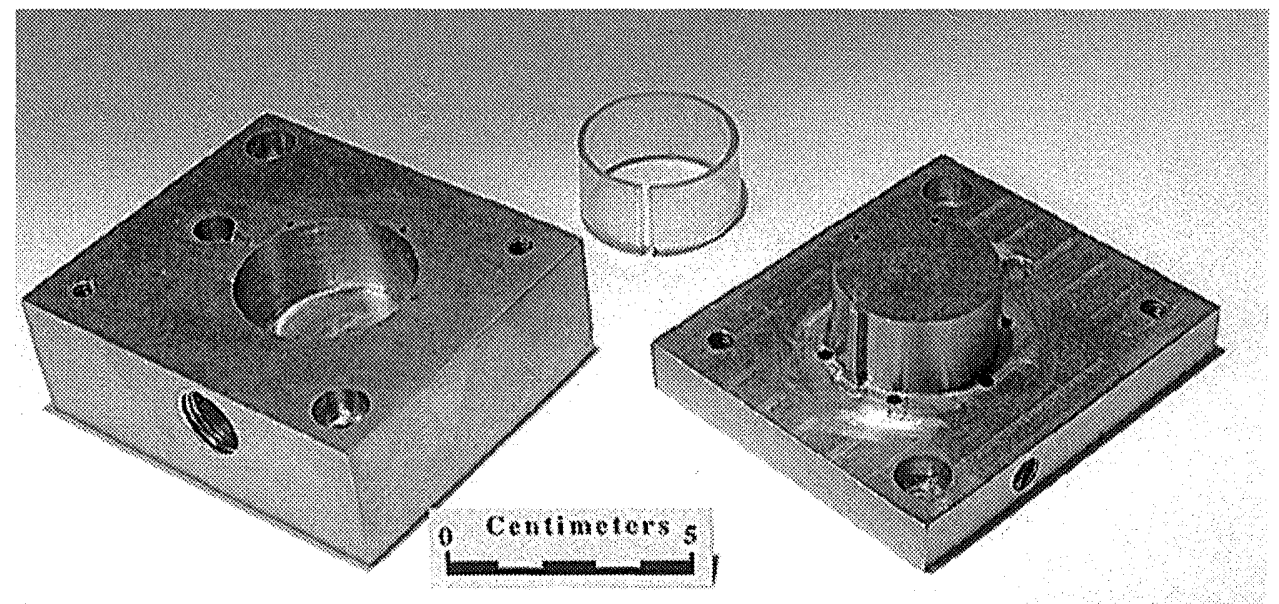

Fig. 9. Infiltrated and machined 3D Printed inserts with conformal cooling channels.

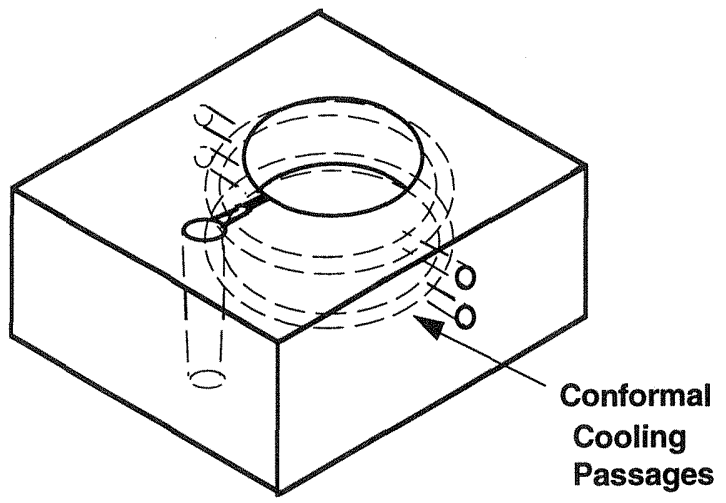

(A)

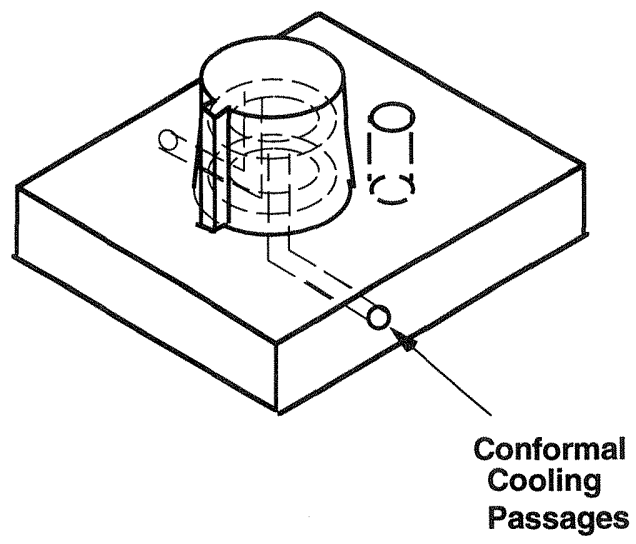

(B)

Fig. 10. Cooling channel placement in the 3D Printed cavity (A) and core (B) inserts. 


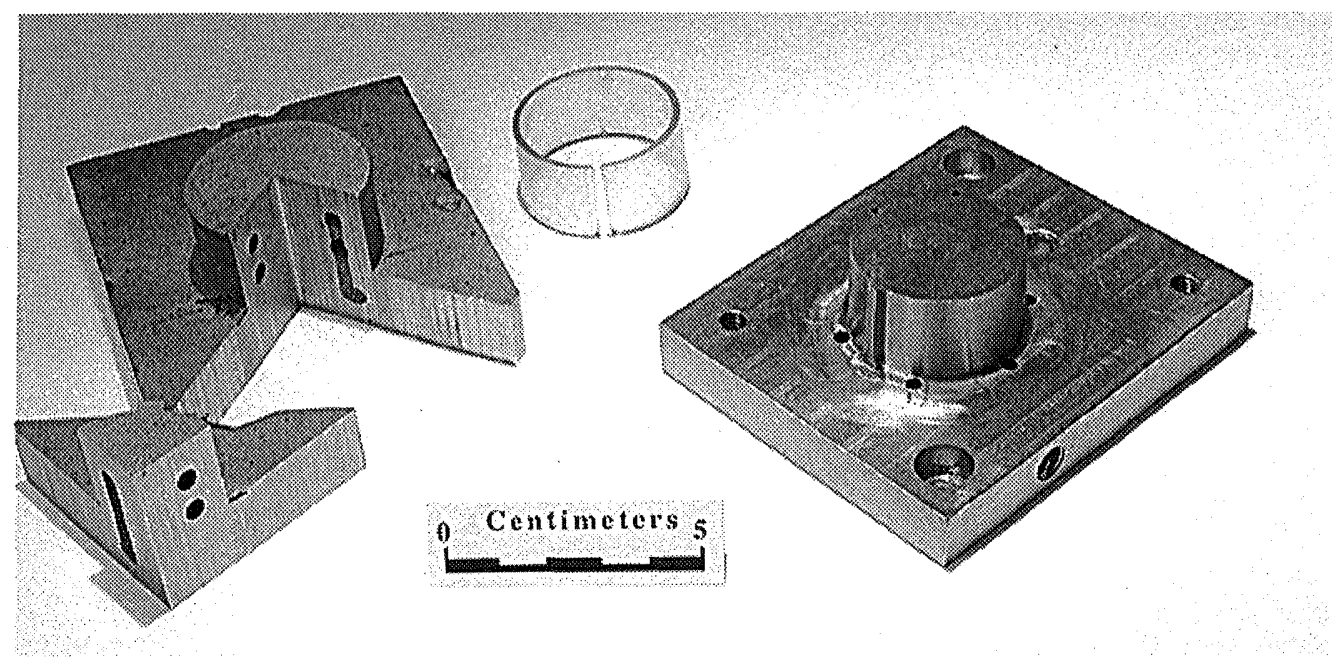

Fig. 11. Infiltrated and machined 3D Printed core insert (right) and an infiltrated core insert that has been cut open to reveal the conformal cooling channels. (left)

Conformal channel placement in the 3D Printed inserts was designed based on the order of magnitude calculations discussed previously. This design simply places the conformal channels a constant distance $(3.18 \mathrm{~mm})$ from the molding surface.

In order to measure the temperature of the molding surface, three thermocouples were placed in the cavity and the core inserts. Thermocouple holes $1.5 \mathrm{~mm}$ in diameter were drilled such that the closest edge of the hole was less than $0.38 \mathrm{~mm}$ from the mold surface at the mid point of the height of the ring. One thermocouple was placed near the gate, one near the rib and one inbetween the gate and the rib. The thermocouples were placed in the holes with a highly thermally conductive paste. Fig. 12 depicts a cross-section of the mating core and cavity inserts.

\section{Experimental Design}

Experimental results focus on a comparison between the mold surface temperature of the inserts with straight channels and the $3 D$ Printed inserts with conformal channels. An Engel EC88, 30 ton injection molding machine located at MIT was used to mold the polystyrene parts with the stainless steel inserts and the 3D Printed inserts. Melt temperature and injection hold pressure were $215^{\circ} \mathrm{C}$ and $1000 \mathrm{psi}$, respectively in all experiments. An injection speed of $1.8 \mathrm{in} / \mathrm{sec}$ was used. Approximately 25 - 30 polystyrene parts were injection molded in a single run. Temperature data was recorded from the six thermocouples placed near the molding surface. Two water reservoirs were used to maintain a constant coolant temperature and were connected to a pressurized nitrogen tank. The reservoirs were connected in parallel to the core and cavity inserts to provide a flow rate of $1.3 \mathrm{gal} / \mathrm{min}$ through each insert. 

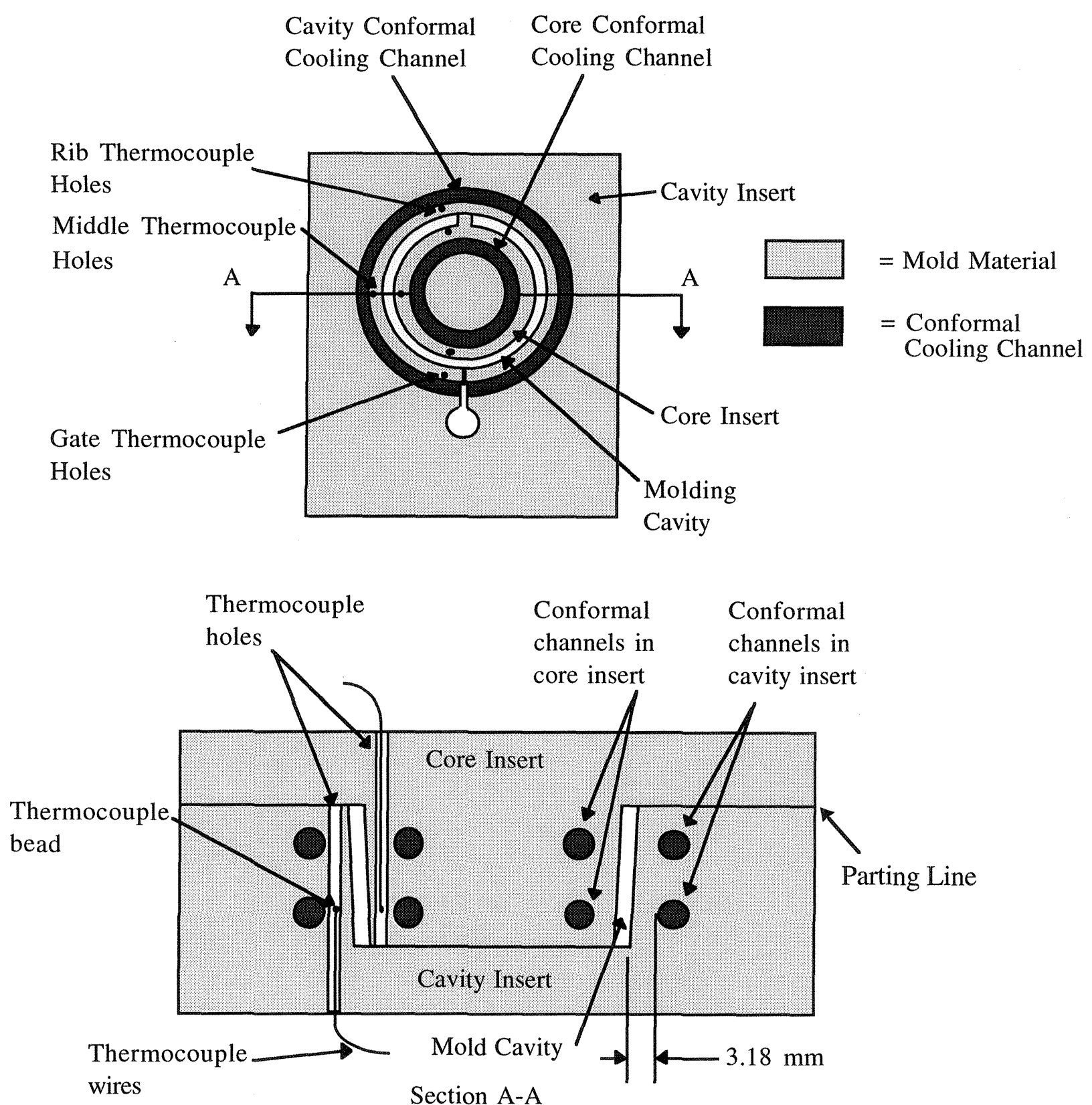

Fig. 12. Thermocouple placement in cross sections of the core and cavity mold pair forming the mold cavity. (Two drawings are of different scale)

\section{Mold Surface Temperature Results}

Mold surface temperature measurements were obtained for the 303 stainless steel inserts with straight channels and the 3D Printed inserts with conformal channels. The coolant temperature was approximately $11^{\circ} \mathrm{C}$ in all injection molding runs. A cycle time of approximately 11 seconds was used for all experiments. This cycle time was chosen based on the minimum cycle time that could 
be obtained using the inserts with straight channels. A slightly shorter cycle time was possible using the inserts with conformal channels, however, for comparison with the straight channel inserts the cycle time was set to 11 seconds. Fig. 13 compares the mold surface temperature near the gate (gate thermocouple hole) for the straight channel core insert and the conformal channel core insert. Each temperature swing represents one shot. Data for the surface temperature near the middle and rib depict similar results.
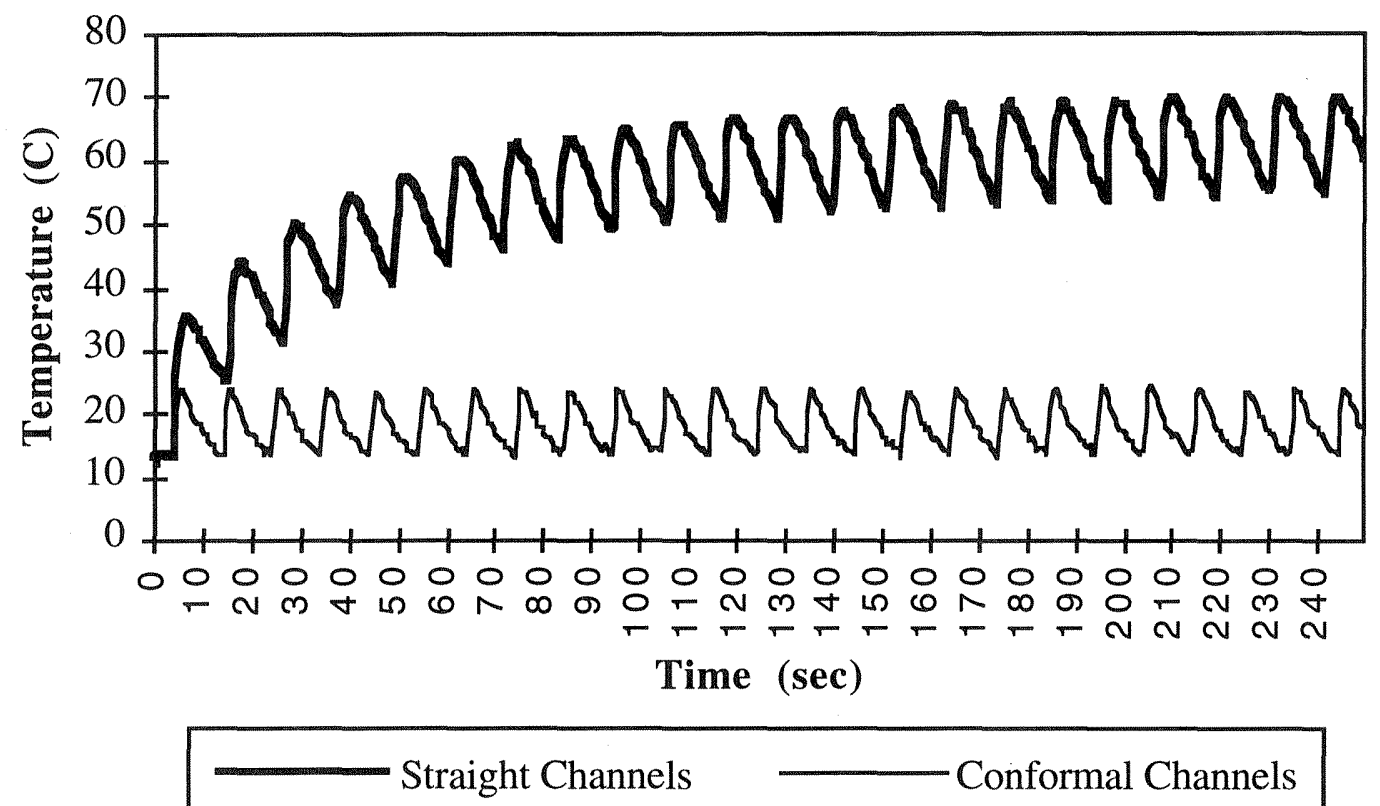

Fig. 13. Mold surface temperature vs. time for straight channel core insert and conformal channel core insert.

Fig. 14 depicts the core surface temperature of the 303 stainless steel inserts with straight channels during an injection molding run. The mold surface temperature history is depicted for the three mold surface locations (gate - middle - rib). This figure is an enlargement of the 19th injection cycle (after the upward cycle drift has leveled off) in Fig. 13, depicting the timing of the three stages. For each shot the temperature rises quickly during the filling stage because the polystyrene plastic is very hot. This filling stage takes approximately 1.0 second. The mold surface temperature drops during the 6.5 second cooling stage. Finally the mold is opened and the part is ejected. This open stage takes approximately 3.5 seconds. During this stage the mold is still cooling. The mold closes again and the cycle starts over. 
The measured ring gap is significantly less than the rib on the core that creates this gap. In other words the ring naturally tends to close. This is true for the inserts with straight channels and the 3D Printed inserts with conformal channels.

A hypothesis for this natural ring closure results from the geometry difference between the core and cavity. Heat can travel radially outward in the cavity whereas it must travel radially inward in the core. This creates some degree of heating of the core relative to the cavity. The hotter core insert causes the core half of the part to cool later than the cavity half of the part. This in turn creates a tension on the core side of the part and causes the ring to curl inward.

The results of this study show that the gap width drifts to a lower steady state dimension during the injection molding run when using the stainless steel inserts with straight channels. The first 5 or 6 molded parts show a downward drift in gap width. This drift in dimension is consistent with the upward drift in mold surface temperature in the core insert with straight channels.

The parts molded with the 3D Printed inserts show no drift in dimension of the gap width. The gap width remains constant from the first shot to the next throughout the injection molding run.

Injection molding runs were completed using three different temperatures of coolant. TABLE I describes the average gap width obtained using the different combinations of coolant temperatures investigated. Twenty six parts were measured for each data set.

TABLE I

Average part gap width for different coolant temperatures. (Parts molded using 3D Printed inserts with conformal channels)

\begin{tabular}{|c|c|c|c|c|}
\hline & & \multicolumn{3}{|c|}{ Cavity Insert } \\
\hline & & $11^{\circ} \mathrm{C}$ & $25^{\circ} \mathrm{C}$ & $54^{\circ} \mathrm{C}$ \\
\hline \multirow{3}{*}{ Core Insert } & $11^{\circ} \mathrm{C}$ & $\begin{array}{c}0.95 \mathrm{~mm} \text { Avg } \\
0.02 \mathrm{~mm} \text { St. Dev }\end{array}$ & $\begin{array}{l}1.38 \mathrm{~mm} \\
0.03 \mathrm{~mm}\end{array}$ & $\begin{array}{l}2.34 \mathrm{~mm} \\
0.02 \mathrm{~mm}\end{array}$ \\
\hline & $25^{\circ} \mathrm{C}$ & $\begin{array}{c}0.0 \mathrm{~mm} \\
-\end{array}$ & $\begin{array}{l}1.05 \mathrm{~mm} \\
0.03 \mathrm{~mm}\end{array}$ & $\begin{array}{l}1.65 \mathrm{~mm} \\
0.03 \mathrm{~mm}\end{array}$ \\
\hline & $54^{\circ} \mathrm{C}$ & $\begin{array}{c}0.0 \mathrm{~mm} \\
-\end{array}$ & $\begin{array}{c}0.0 \mathrm{~mm} \\
-\end{array}$ & $\begin{array}{l}0.93 \mathrm{~mm} \\
0.02 \mathrm{~mm}\end{array}$ \\
\hline
\end{tabular}

When the coolant running through the cavity insert is significantly hotter than the coolant running through the core insert, the measured gap width is increased. When the coolant running through the cavity insert is significantly colder than the coolant running through the core insert, the measured gap closes. This result is evidenced in TABLE I. Again the side of the polystyrene part to cool last determines the gap width. Thus, by varying coolant temperature in the core and cavity inserts a part with a given gap width may be obtained. 


\section{FINITE DIFFERENCE MODEL OF TOOLING}

\section{A. Model Description}

The model predicts the performance of various conformal cooling channel designs. This model was necessary to develop the final conformal channel design for the 3D Printed inserts. The inputs to the model include the thermal properties of the plastic (polystyrene), and bronze infiltrated 316L stainless steel mold material, mold filling time, cooling time and ejection time in the simulated injection molding cycle, the physical dimensions of the cooling channel, mold and plastic melt area, coolant temperature and plastic melt temperature.

A two-dimensional explicit numerical finite difference formulation is used to solve the unsteady heat transfer problem. For simplicity, the mold and plastic melt were modeled as a rectangular mold block with a thin rectangular strip of plastic on one face of the block. Filling is simulated by the movement of this plastic "strip" from the gate end to the rib end (point at which plastic flow melt meets a physical barrier) across the face of the mold block. Fig. 17 depicts a schematic of the model geometry.

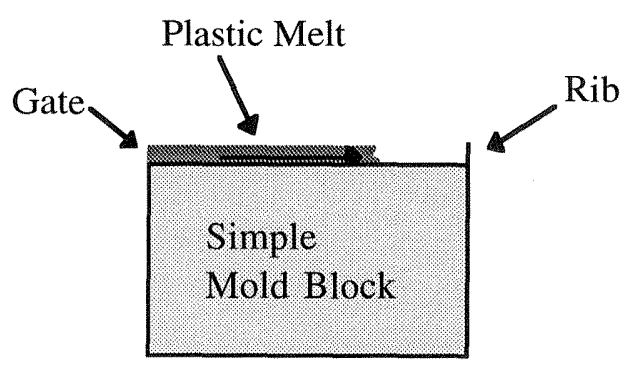

Fig. 17. Representation of the two-dimensional model.

Details of the model formulation will be left for other publications.

\section{B. Simulation Results}

Fig. 18 shows the results of the finite difference simulation of the heat transfer in the inserts with conformal channels during an injection molding run. 


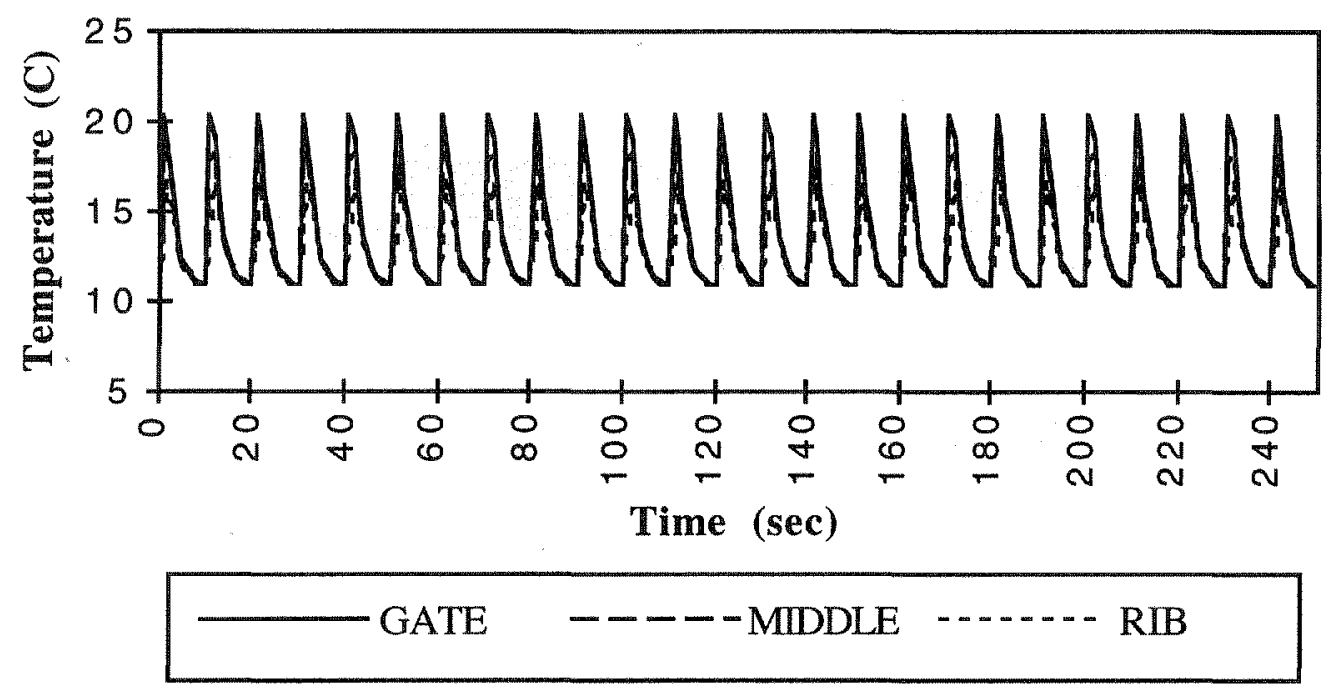

Fig. 18. Finite difference simulation - conformal channels

(3D Printed Inserts) - Coolant Temperature $=11^{\circ} \mathrm{C}$

The results of this finite difference analysis may be compared to the experimental results of the surface temperature versus time data for the 3D Printed core insert. Fig. 19 depicts one cycle of the simulation and one cycle of the experimental mold surface temperature data derived from the gate thermocouple. Fig. 20 depicts the same comparison at the rib thermocouple. The simulation plots have been shifted on the time scale to synchronize the cycle starting time with that of the experimental data.

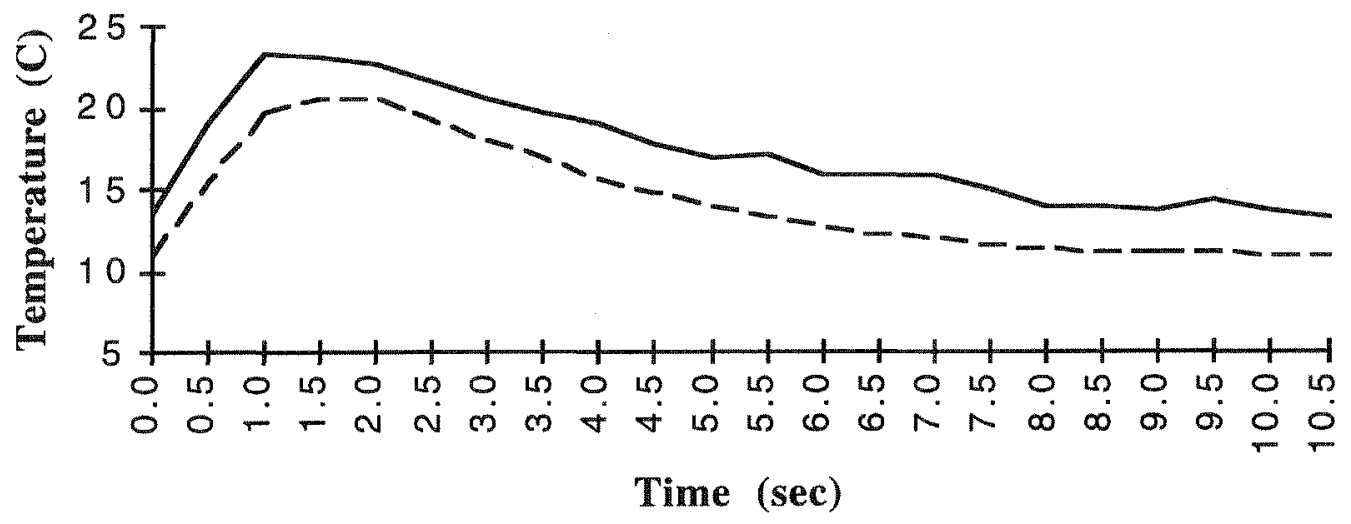

GATE - Experimental - - - - GATE - Simulation

Fig. 19. Simulation and experimental results for core insert with conformal channels. 

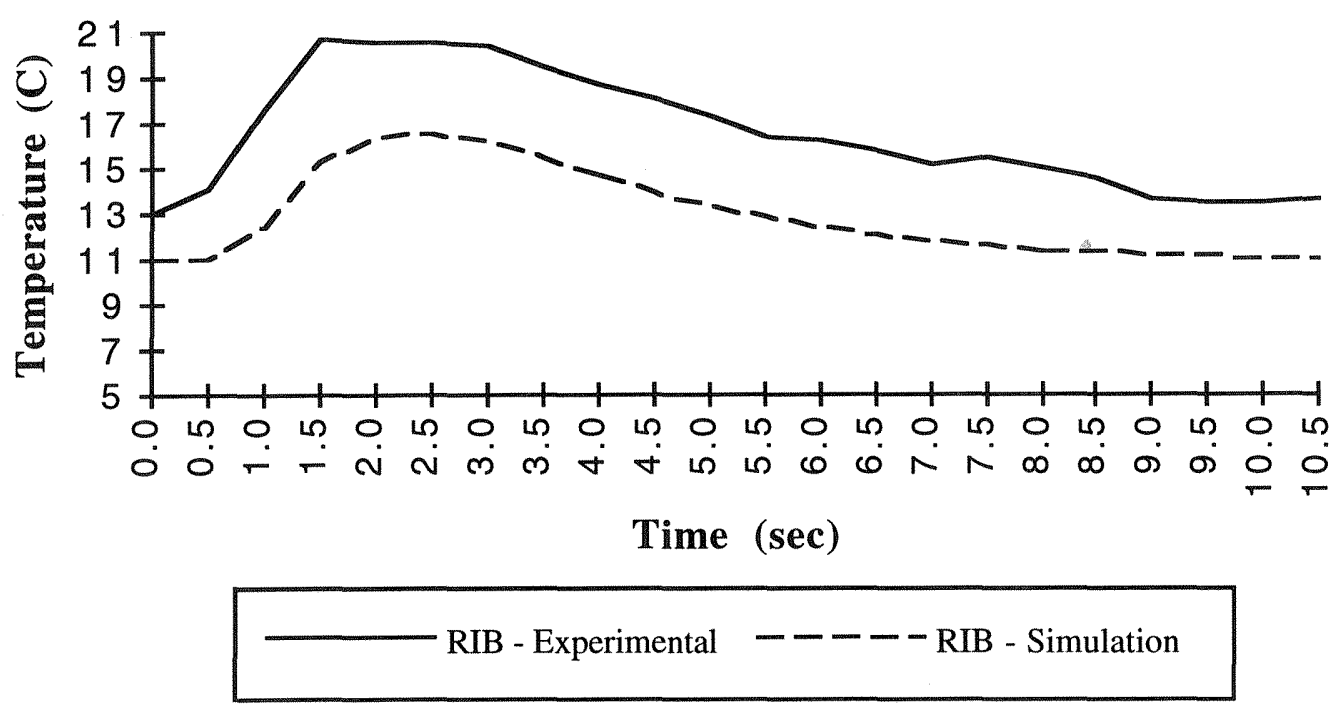

Fig. 20. Simulation and experimental results for core insert with conformal channels.

The experimental and finite difference surface temperature plots have very similar shape. A temperature rise of the molding surface of approximately $10{ }^{\circ} \mathrm{C}$ is observed in both the experimental and simulation plots. A difference in surface temperature at the beginning of the cooling cycle between the mold surface at the gate and the mold surface at the rib of approximately $4-5{ }^{\circ} \mathrm{C}$ is detected in both plots.

\section{CONCLUSIONS}

The freedom to create internal geometry by 3DP allows for the fabrication of molds with internal cooling passages. These passages produced with the 3DP process will provide the ability to control accurately the temperature of the molding cavity throughout the process cycle resulting in lower residual stress and faster production.

A preliminary investigation was established analyzing the effects of conformal cooling channels on mold surface uniformity and control. A direct comparison was obtained of the mold surface temperature during the injection cycle of a 3D Printed mold (core and cavity inserts) with conformal channels and an identical mold machined of 303 stainless steel with conventional straight channels. Surface temperature measurements demonstrated that the inserts with conformal cooling channels exhibited a more uniform surface temperature than the inserts machined with straight channels. Numerical modeling gave results similar to the experimental results, providing some confidence in the ability to design such tooling in the future.

\section{ACKNOWLEDGMENTS}

The National Science Foundation under the Strategic Manufacturing Initiative (contract number 9215728-DDM), the Technology Re-Investment Project, Cooperative Agreement (DMI 9420964) and the members of the Three Dimensional Printing Industrial Consortium have supported the project with valuable suggestions and resources. 


\section{REFERENCES}

German, R.M., Powder Metallurgy Science, Metal Powder Industries Federation, Princeton, NJ, 1984.

Gordon, M.J., Total Quality Process Control for Injection Molding, Hanser Publishers, New York, NY, 1993.

Lyman, T., Metals Handbook Eighth Edition, Powder Metallurgy, vol. 1, American Society for Metals, Metals Park, OH, 1961.

Menges, G., How to Make Injection Molds, Hanser Publishers, Munich, 1993.

Michaels, Steven, "Production of Metal Parts Using the Three Dimensional Printing Process," M.I.T. Masters Thesis, November, 1993.

Michaels, S., Sachs, E., Cima, M., "Three Dimensional Printing of Metal and Cermet Parts", Proceedings $\mathrm{P} / \mathrm{M}^{2} \mathrm{TEC}$ ' 94 Conference - Advances in Powder metallurgy and Particulate materials, May 8-11, 1994, Toronto, Canada.

Sachs, E., Cima, M., Bredt, J., Curodeau, A., "CAD-Casting: The Direct Fabrication of Ceramic Shells and Cores by Three Dimensional Printing", Manufacturing Review, Vol 5, No 2, June 1992, pp 118-126.

Sachs, E., Cima, M., Williams, P., Brancazio, D., and Cornie, J., "Three Dimensional Printing: Rapid Tooling and Prototypes Directly From a CAD Model", Journal of Engineering for Industry, Vol 114, No. 4, November 1992, pp 481-488.

Semenchenko, V.K., Surface Phenomena in Metals and Alloys, Pergamon Press LTD., Oxford, 1962.

Shutts, Christopher, "Development of a Reliable Electrostatic Multijet Printhead for Three Dimensional Printing," M.I.T. Masters Thesis, May, 1995.

Thomas, L. C., Fundamentals of Heat Transfer, Prentice-Hall, Inc., Englewood Cliffs, NJ, 1980. 